\title{
MODEL PEMBELAJARAN DISCOVERY BASED UNITY OF SCIENCE (DBUS) DENGAN PENDEKATAN SETS: PENGARUH TERHADAP KEMAMPUAN BERPIKIR KRITIS PADA MASA PANDEMI COVID-19
}

\author{
$\operatorname{Irma}^{1}$, Meriyati $^{2}$, Irwandani $^{3 *}$ \\ 1,2 Prodi Pendidikan Fisika FTK UIN Raden Intan Lampung \\ ${ }^{3}$ Prodi Pendidikan Islam Anak Usia Dini FTK UIN Raden Intan Lampung \\ *Coressponding author: irwandani@ radenintan.ac.id
}

Article History:

Received: maret 02, 2021

Revised: maret 21, 2021

Accepted: mei 01, 2021

Published: juni 25, 2021

Keywords: Berpikir kritis, model DBUS, pendekatan SETS

\begin{abstract}
The purpose of this study was to analyze the effect of the Discovery Based Unity of Science (DBUS) learning model with the SETS approach on students' critical thinking skills during the covid-19 pandemic. The essay test instrument used in this study amounted to 9 questions. The research was conducted at MTs Hasanuddin Bandar Lampung. This study uses a quasi-experimental method. The sampling technique used is simple random sampling, with class VIII $A$ as the experimental class and class VIII $B$ as the control class. The research data were tested using normality, homogeneity, and hypothesis testing. The results of the $N$-Gain test in the experimental class showed results of 0.53 in the medium category, while in the control class the results showed 0.16 in the low category. Based on the research data, it was found that the data were normally distributed and homogeneous, so a t-test was carried out with a significant level of 0.05. The results show that tcount>ttable, which is 2.04>2.03, which means $\mathrm{HO}$ is rejected and $\mathrm{Ha}$ is accepted. This shows that there is a significant influence on the application of the Discovery Based Unity of Science (DBUS) learning model with the SETS approach to students' critical thinking skills during learning in the covid-19 pandemic era.
\end{abstract}

\begin{abstract}
Abstrak: Tujuan penelitian ini untuk menganalisis pengaruh model pembelajaran Discovery Based Unity of Science (DBUS) dengan pendekatan SETS terhadap kemampuan berpikir kritis peserta didikpada masa pandemic covid-19. Instrumen tes soal uraian yang digunakan pada penelitian ini sebanyak 9 soal. Penelitian dilakukan di MTs Hasanuddin Bandar Lampung. Penelitian ini menggunakan metode quasy eksperiment. Pengambilan sampel menggunakan teknik simple random sampling, dengan kelas VIII A sebagai kelas eksperimen dan kelas VIII B sebagai kelas kontrol. Hasil penelitian yang telah diperoleh diuji menggunkan uji normalitas, homogenitas, dan uji hipotesis. Uji $\mathrm{N}$-Gain Kelas eksperimen 0.53 dengan kategori sedang dan kelas kontrol 0.16 dengan kategori rendah. Berdasarkan data hasil penelitian diperoleh bahwa data terdistribusi normal dan homogen, sehingga dilakukan uji-t dengan taraf signifikan 0,05 diperoleh hasil $\mathrm{T}_{\text {hitung }}>\mathrm{T}_{\text {tabel }}$ sebesar 2,04 $>2,03$ yang berarti Ho ditolak dan Ha diterima. Hal ini menunjukkan bahwa terdapat pengaruh model pembelajaran Discovery Based Unity of Science (DBUS) dengan pendekatan SETS.
\end{abstract}

\section{PENDAHULUAN}

Pendidikan dapat mengangkat derajat manusia ke arah yang bermoral, berkarakter baik, mempunyai nilai serta sikap yang mencerminkan bahwa manusia sebagai insan kamil yang seutuhnya
(Sukitman, 2016). Pendidikan sebagai proses pembudayaan, proses kultural, atau proses pengembangan bakat dan potensi (Makwinja, 2020; Purwanto et al., 2021; Rofiqah et al., 2020). 
Proses pendidikan diharapkan dapat memperoleh hasil pembelajaran yang baik, artinya pendidikan sangat erat kaitannya dengan pembelajaran sehingga sangat sulit dipisahkan dan dibedakan (Susiloningsih, 2016). Faktor yang dapat mempengruhi keberhasilan peserta didik meliputi faktor internal yang berasal dari peserta didik itu sendiri dan faktor eksternal yang berasal dari lingkungan keluarga, sekolah serta lingkungan masyarakat (Kristin, 2016).

Kecenderungan perubahan dalam dunia pendidikan terus terjadi dan berkembang dalam memasuki abad ke-21 (Budiman, 2017). Kompetensi abad ke-21 yang meliputi keterampilan hidup dan karir, keterampilan inovasi dan belajar yang kemudian dikenal dengan istilah 4C (critical thinking, communication, collaboration, dan creativity) (Khasanah et al., 2019). Pembelajaran 4C dapat menumbuhkan rasa ingin tahu peserta didik, dapat memahami konsep serta mampu menyelesaikan masalah pada berbagai bidang salah satunya pada bidang sains yaitu pembelajaran fisika (Ade et al., 2018).

Proses pembelajaran fisika, peserta didik diberi kesempatan untuk mengkonstruksi konsep sendiri, sehingga akan memberikan pengalaman langsung untuk menjelajahi dan memahami alam sekitar secara ilmiah (Ida Fitriyani, 2017). Oleh karena itu, peserta didik perlu dilatih untuk memahami konsep-konsep dalam menyelesaikan permasalahan serta pengalaman belajar yang nyata, sehingga dapat meningkatkan kemampuan berpikir kritis (Khoiri et al., 2020; Kim \& Choi, 2020; Risdianto et al., 2020; Wahyudi et al., 2020).

Kemampuan berpikir kritis merupakan kemampuan yang berguna untuk menstimulasi kemampuan lainnya, seperti berpikir logis, kreatif, memecahkan masalah, penggunaan teknologi serta kemampuan beradaptasi terhadap berbagai perubahan dan perkembangan zaman (Defiyanti \& Sumarni, 2019; Moch Alif Mahfudin et al., 2020). Kompetensi berpikir kritis yaitu bentuk berpikir peserta didik yang tersusun secara sistematis sehingga dalam proses berpikir kritis bisa menganalisis, mengevaluasi dan menyimpulkan (Qurniati et al., 2015).

Beberapa peneliti telah berupaya meningkatkan berpikir kritis melalui model pembelajaran Discovey Based Unity of Science (DBUS) (Khasanah, 2018; Khasanah et al., 2019), selain itu juga telah di integrasikan pendekatan Science, Environment, Technology and, Society (SETS) pada pembelajaran (Komariah et al., 2015; Rini, 2017). Fokus pada penelitian ini mengintegrasikan keduanya dalam pembelajaran fisika yaitu menganalisis pengaruh model pembelajaran Discovey Based Unity Of Science (DBUS) dengan pendekatan SETS terhadap kemampuan berpikir kritis peserta didik.

\section{METODE PENELITIAN}

Penelitian ini berlangsung pada masa pandemi covid-19 sehingga kegiatan belajar mengajar digantikan dengan pembelajaran secara online dengan menggunakan media atau aplikasi yang memadai. Peneliti menggunakan aplikasi whatsApp untuk membantu proses pembelajaran.

Penelitian ini dilaksanakan di MTs Hasanuddin Bandar Lampung daan waktu penelitian dilaksanakan pada semester ganjil tahun ajaran 2020/2021. Sampel yang digunakan dalam penelitin kelas VIII A sebagai kelas eksperimen dan kelas VIII B sebagai kelas kontrol .

$$
\text { Penelitian menggunakan }
$$
instrumen tes kemampuan berpikir kritis, wawancara, observasi dan dokumentasi. Bentuk tes berupa soal uraian sebanyak 9 soal. Jenis penelitian ini kuasi eksperimen. Desain penelitian yang digunakan dalam penelitian ini adalah 
nonrandomized control group pretestposttest desain.

\section{HASIL DAN PEMBAHASAN}

Data hasil tes kemampuan berpikir kritis peserta didik dikumpulkan dalam dua tahapan yaitu, sebelum diberi perlakuan (pretest) dan sesudah diberi perlakuan (posttest). Data tersebut disajikan dalam tabel 1 berikut:

Tabel 1. Hasil pretest dan posttest

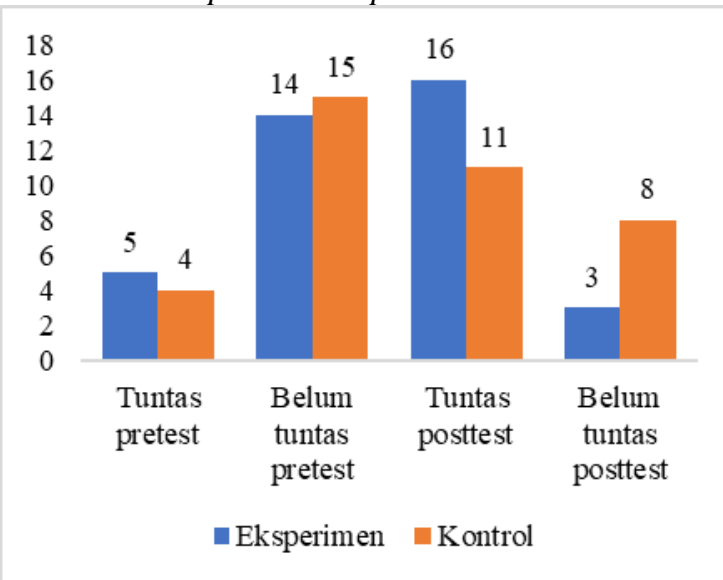

Hasil pretest-posttest yang diperoleh digunakan sebagai perhitungan $N$-Gain untuk melihat peningkatan atas perlakuan yang telah dilakukan pada kelompok eksperimen maupun kelas kontrol. Nilai N-Gain pada kelas eksperimen yaitu 0,53 dan nilai N-Gain kelas kontrol yaitu 0,16. Berdasarkan hasil $N$-Gain kelas eksperimen dengan menerapkan model pembelajaran Discovery Based Unity of Scince (DBUS) dengan pendekatan SETS lebih tinggi dibandingkan dengan kelas kontrol. Seperti pada tabel berikut:

Tabel 2. Uji N-Gain

\begin{tabular}{lll}
\hline Kategori & Eksperimen & Kontrol \\
\hline Rata-rata & 0,53 & 0,16 \\
\hline Kriteria & Sedang & Rendah \\
\hline
\end{tabular}

Selanjutnya di uji dengan uji normalitas dan homogenitas disajikan pada tabel 3 dan tabel 4 berikut:
Tabel 3. Uji Normalitas

\begin{tabular}{lllll}
\hline \multirow{2}{*}{ Statistik } & \multicolumn{2}{c}{ Eksperimen } & \multicolumn{2}{c}{ Kontrol } \\
& Pretest & Posttest & Pretest & Posttest \\
\hline $\mathrm{L}_{\text {hitung }}$ & 0,111 & 0,157 & 0,081 & 0,102 \\
$\mathrm{~L}_{\text {tabel }}$ & 0,195 & 0,195 & 0,195 & 0,195 \\
Kesimpulan & \multicolumn{2}{c}{ Normal } & \multicolumn{2}{c}{ Normal } \\
\hline
\end{tabular}

Tabel 4. Uji Homogenitas

\begin{tabular}{lll}
\hline \multicolumn{1}{c}{ Statistik } & \multicolumn{1}{c}{ Pretest } & \multicolumn{1}{c}{ Posttest } \\
\hline $\mathrm{F}_{\text {tabel }}$ & 0,451 & 0,451 \\
$\mathrm{~F}_{\text {hitung }}$ & 0,455 & 1,135 \\
Kesimpulan & Homogen & Homogen \\
\hline
\end{tabular}

Setelah data bersifat normal dan homogen, selanjutnya dilakukan analisis uji $t$-test. Hasil uji $t$-test ditunjukkan pada tabel 5 berikut.

Tabel 5. Uji t-test

\begin{tabular}{ccc}
\hline Kelompok & Eksperimen & Kontrol \\
\hline Jumlah siswa & 19 & 19 \\
$\mathrm{~T}_{\text {tabel }}$ & 2,028 \\
$\mathrm{~T}_{\text {hitung }}$ & 2,044 \\
Hasil & $\mathrm{T}_{\text {hitung }}>\mathrm{T}_{\text {tabel }}$ \\
Kesimpulan & Ho ditolak Ha diterima
\end{tabular}

Tabel 5 menunjukkan bahwa terdapat peningkatan yang signifikan kemampuan berpikir kritis peserta didik sebelum diberikan perlakuan dengan model pembelajaran dan sesudah diberi perlakuan dengan model pembelajaran. Hasil perhitungan $u j i-t$ sebesar $t_{\text {hitung }}>t_{\text {tabel }}$ yaitu 2,04>2,03. Maka dapat simpulkan bahwa $\mathrm{H}_{\mathrm{o}}$ ditolakdan $\mathrm{H}_{\mathrm{a}}$ diterima.

Berdasarkan hasil tes diketahui bahwa, rata-rata nilai kemampuan berpikir kritis peserta didik kelas eksperimen yang menggunakan model Discovery Based Unity of Scince (DBUS) dengan pendekatan Science, Environment, Technology and, Society (SETS) lebih besar dibandingkan rata-rata nilai kelas kontrol yang menggunakan model Discovery Learning. Hasil rata-rata nilai dari posttest kedua kelas tersebut jika dibandingkan dengan nilai rata-rata pretest, maka terlihat jelas dari kedua kelas mendapatkan peningkatan 
kemampuan berpikir kritis setelah diberikan perlakuan model pembelajaran. masing kelas ditunjukkan pada tabel 6 Storyboard yang dilakukan pada masingberikut.

Tabel 6. Storyboard penelitian

\begin{tabular}{|c|c|c|c|}
\hline Sintak DBUS & SETS & Kegiatan Pendidik & Kegiatan Peserta Didik \\
\hline $\begin{array}{l}\text { Stimulation } \\
\text { using local } \\
\text { wisdom }\end{array}$ & $\begin{array}{lr}\text { - Society: } & \text { Mengamati } \\
\text { lingkungan } & \text { tempat } \\
\text { tinggal } & \end{array}$ & $\begin{array}{l}\text { Pendidik memberi informasi } \\
\text { untuk melakukan pengenalan } \\
\text { atau pengamatan terkait usaha } \\
\text { dan pesawat sederhana yang } \\
\text { ada di lingkungan tempat } \\
\text { tinggal peserta didik. }\end{array}$ & $\begin{array}{l}\text { Melakukan pengenalan } \\
\text { atau pengamatan sesaui } \\
\text { arahan yang diberikan oleh } \\
\text { pendidik. }\end{array}$ \\
\hline $\begin{array}{l}\text { Problem } \\
\text { statement }\end{array}$ & $\begin{array}{l}\text { - Science: Memberikan } \\
\text { gambaran materi } \\
\text { usaha dan pesawat } \\
\text { sederhana } \\
\text { - Society: mengamati } \\
\text { lingkungan sekitar }\end{array}$ & $\begin{array}{l}\text { Memberikan sedikit penjelasan } \\
\text { terkait materi usaha dan } \\
\text { pesawat sederhana agar } \\
\text { peserta didik mampu } \\
\text { mengamati lingkungan sekitar } \\
\text { sesuai materi yang di pelajari. }\end{array}$ & $\begin{array}{l}\text { Melakukan kegiatan } \\
\text { menemukan, merumuskan } \\
\text { masalah yang mengacu } \\
\text { pada isu yang terdapat di } \\
\text { lingkungan sekitar. }\end{array}$ \\
\hline $\begin{array}{l}\text { Observation \& } \\
\text { data } \\
\text { collections }\end{array}$ & $\begin{array}{l}\text { - Science: Menyusun } \\
\text { rencana untuk } \\
\text { melakukan } \\
\text { pengamatan } \\
\text { - Technology: } \\
\text { Menampilkan video } \\
\text { pesawat sederhana }\end{array}$ & $\begin{array}{l}\text { Mengarahkan peserta didik } \\
\text { membuat rencana untuk } \\
\text { melakukan pengamatan agar } \\
\text { sesuai dengan apa yang } \\
\text { diinginkan. }\end{array}$ & $\begin{array}{l}\text { Mendengarkan dan } \\
\text { memahami apa yang } \\
\text { disampaikan oleh pendidik } \\
\text { untuk membuat rencana } \\
\text { atau langkah-langkah } \\
\text { pengamatan yang akan } \\
\text { dilakukan. } \\
\text { Melihat video yang } \\
\text { ditampilakan oleh pendidik } \\
\text { untuk bahan pengamatan } \\
\text { yang akan dilakukan di } \\
\text { lingkungan sekitar. }\end{array}$ \\
\hline $\begin{array}{l}\text { Data } \\
\text { proscessing }\end{array}$ & $\begin{array}{l}\text { - Science: Menjelaskan } \\
\text { materi usaha dan } \\
\text { pesawat sederhana } \\
\text { - Technology: Membuat } \\
\text { alat peraga pesawat } \\
\text { sederhana }\end{array}$ & $\begin{array}{l}\text { - Menjelaskan terkait materi } \\
\text { usaha dan pesawat sederhana } \\
\text { kepada peserta didik. } \\
\text { - mengarahkan peserta didik } \\
\text { untuk dapat membuat alat } \\
\text { peraga sederhana terkait } \\
\text { materi. }\end{array}$ & $\begin{array}{l}\text { - Mendengarkan } \\
\text { penjelasan pendidik } \\
\text { untuk lebih memahami } \\
\text { dan lebih mudah untuk } \\
\text { melakukan pengamatan } \\
\text { di lingkungan sekitar. } \\
\text { - membuat alat peraga } \\
\text { sederhana dengan arahan } \\
\text { yang sudah dijelaskan } \\
\text { oleh pendidik melalui } \\
\text { video yang ditampilkan. }\end{array}$ \\
\hline $\begin{array}{l}\text { Verivication } \\
\text { base on } \\
\text { religion }\end{array}$ & $\begin{array}{l}\text { - Science: } \\
\text { materi usaha dan } \\
\text { pesawat seserhana } \\
\text { berdasarkan Ayat Al- } \\
\text { qur'an } \\
\text { - Environment: } \\
\text { Mengaitkan antara } \\
\text { ayat al-qur'an dwngan } \\
\text { kegiatan yang } \\
\text { dilakukan } \\
\text { lingkungan sekitar. }\end{array}$ & $\begin{array}{l}\text { - Menjelaskan materi yang } \\
\text { berhubungan dengan ayat al } \\
\text { quran agar pembelajaran } \\
\text { lebih menarik. } \\
\text { - Mengarahkan peserta didik } \\
\text { untuk mengaitkan antara } \\
\text { materi yang sudah dipelajari } \\
\text { dengan ayat al quran sesuai } \\
\text { dengan pengamatan yang } \\
\text { telah dilakukan di } \\
\text { lingkungan sekitar. }\end{array}$ & $\begin{array}{l}\text { Membuat Kesimpulan } \\
\text { terkait hasil pengamatan } \\
\text { dan mengintegrasikan } \\
\text { dengan ayat al qur an }\end{array}$ \\
\hline $\begin{array}{l}\text { Generalization } \\
\text { awareness }\end{array}$ & $\begin{array}{l}\text {-Science: } \\
\text { Menyimpulkan } \\
\text { pengamatan }\end{array}$ & $\begin{array}{l}\text { - Memberikan kesimpulan dan } \\
\text { pengutan terkait materi yang } \\
\text { telah dipelajari secara ilmiah. }\end{array}$ & $\begin{array}{lr}\text { Mampu memberikan } \\
\text { kesimpulan mereview dan } \\
\text { mengevaluasi } & \text { hasil } \\
\text { pengamatan yang telah } \\
\text { dilakukan. }\end{array}$ \\
\hline
\end{tabular}


Berdasarkan tabel 6 dijelaskan secara rinci terkait dengan penerapan pada proses pembelajaran. Terdapat enam sintak pada model pembelajaran Discovery Based Unity of Scince (DBUS). Model DBUS diintegrasikan dengan pendekatan Science, Environment, Technology and, Society (SETS) sehingga mampu merangsang ketertarikan belajar peserta didik. Ketertarikan peserta didik merangsang mudah memahami materi (Indraswati et al., 2021; Makhrus et al., 2021), selain itu adanya beberapa media yang digunakan pada pembelajaran membuat peserta didik mampu berpikir kritis (Kuntarto, 2018; Moch Alif Mahfudin et al., 2020; Sari et al., 2021). Temuan pada penelitian ini, model pembelajaran Discovery Based Unity of Scince (DBUS). Model DBUS diintegrasikan dengan pendekatan Science, Environment, Technology and, Society (SETS) mampu meningkatkan berpikir kritis peserta didik.

\section{SIMPULAN DAN SARAN}

Temuan pada penelitian ini bahwa Model pembelajaran Discovery Based Unity of Scince (DBUS) dengan pendekatan Science, Environment, Technology and, Society (SETS) berpengaruh dalam meningkatkan kemampuan berpikir kritis peserta didik. Hal ini berlandaskan pada hasil uji hipotesis yang telah didapatkan dengan menggunakan Uji-t dengan nilai $\mathrm{T}_{\text {hitung }}>\mathrm{T}_{\text {tabel }}$ yaitu $2,04>2,03$ artinya $\mathrm{H}_{\mathrm{o}}$ ditolak dan $\mathrm{H}_{\mathrm{a}}$ diterima. Peneliti selanjutnya perlu pemilihan model pembelajaran yang bervariasi dan tepat agar indikator dapat tercapai dengan baik.

\section{DAFTAR PUSTAKA}

Ade, N., Wijaya, A. K., \& Kusumawati, I. (2018). Penerapan Model Learning Cycle (LC) 7E Sebagai Upaya
Peningkatan Hasil Belajar Siswa Tentang Zat dan Wujudnya di Kelas VII. Jurnal Ilmu Pendidikan Fisika, 3(2), 42.

Budiman, H. (2017). Peran Teknologi Informasi dan Komunikasi dalam Pendidikan. Al-Tadzkiyyah: Jurnal Pendidikan Islam, 8, 75-83.

Defiyanti, \& Sumarni, W. (2019). Analisis Kemampuan Berpikir Kritis Peserta Didik Pada Penerapan Problem Based Learning Berbantuan Lembar Kerja Peserta Didik Bermuatan Etnosains. Phenomenon, O9(2), 206-218.

Ida Fitriyani, A. H. dan M. (2017). Pengembangan Perangkat Pembelajaran IP Untuk Meningkatkan Kemampuan Berpikir Tingkat Tinggi dan Penalaran Ilmiah Siswa Sekolah Menengah Pertama. Jurnal Pembelajaran Sains, 1(1), 27-28.

Indraswati, D., Gunawan, G., Nursaptini, N., Widodo, A., \& Sutisna, D. (2021). The effectiveness of the Predict Observe Explain (POE) Method and Time Token Arends for Students' Concepts Understanding in the Social Studies Subject. Journal of Physics: Conference Series, 1779(1), 1-5. https://doi.org/10.1088/17426596/1779/1/012079

Khasanah, N. (2018). Memberdayakan Hight Order Thinking Skills (HOTS) Melalui Model Dicovery Based Unity of Science (DBUS). Jurnal Phenomenon, 8(2), 21-24.

Khasanah, N., Prayitno, B. A., \& Walid, A. (2019). Critical Thinking Ability and Student's personal Religious Beliefs: An Analysis of DBUS Model Implementation. Jurnal Keguruan Dan Ilmu Tarbiyah, 4(1), 41-49.

Khoiri, A., Nasokah, Amalia, T., \& Slamet, H. (2020). Analisis Kritis Pendidikan Sains: (Problematika , 
Solusi dan Model Keterpaduan Sains Dasar). SPEKTRA: Jurnal Kajian Pendidikan Sains, 6(1), 19-34.

Kim, Y., \& Choi, M. (2020). Towards critical multicultural teacher education in the midst of ethnonationalism: Korean pre-service teachers ' international learning experiences. Teaching and Teacher Education, 96, 1-11. https://doi.org/10.1016/j.tate.2020.10 3155

Komariah, S., Azmi, N., \& Gloria, R. Y. (2015). Penerapan Pendekatan SETS Dalam Pembelajaran Biologi Berbasis IMTAQ Untuk Meningkatkan Hasil Belajar Siswa Pada Konsep Pencemaran Lingkungan di SMA N 8 Kota Cirebon. Scientiae Educatia, 5(1).

Kristin, F. (2016). Analisis Model Pembelajaran Discovery Learning Dalam Meningkatkan Hasil Belajar Siswa SD. Jurnal Pendidikan Dasar PerKhasa, 90.

Kuntarto, E. (2018). Bahasa dan Kekuasaan Politik Oposan Di Indonesia: Analisis Wacana Kritis. Jurnal Kiprah, 6(2), 37-47. https://doi.org/10.31629/kiprah.v6i2. 860

Makhrus, M., Wahyudi, W., \& Zuhdi, M. (2021). Students' Conceptual Understanding through Implementation of LiveWire in Basic Electronics Virtual Experiment. Jurnal Penelitian Pendidikan IPA, $7(2)$, 249-254. https://doi.org/10.29303/jppipa.v7i2. 705

Makwinja, V. M. (2020). Inclusive and Multicutural Education: The Dynamics of Higher Education Institutions in Botswana Inequality and Exclusion of Students. International Perspectives on Humanizing Higher Education, 30, 85-99.

https://doi.org/10.1108/S2055-

\section{7}

Moch Alif Mahfudin, Hariyono, E., \& Lestari, N. A. (2020). Upaya untuk Melatihkan Keterampilan Berpikir Kritis Peserta Didik SMA pada Masa Pandemi Covid-19 melalui Media Pembalejaran Software Simulasi Gunung Api. IPF: Jurnal Inovasi Pendidikan Fisika, 9(3), 400-409.

Purwanto, G. D., Ulyan, M., \& Basit, A. (2021). Implementation of Industrial Based Islamic Education Management in Pesantren Darussalam Al-Fatah Cilacap. Budapest International Research and Critics in Linguistics and Education (BirLE) Journal, 4(1), 630-641.

Qurniati, D., Andayani, Y., \& Words, K. (2015). Peningkatan keterampilan Berpikir Kritis Melalui Model Pembelajaran Dicovery Learning. Journal Penelitian Pendidikan IPA, 1(2).

Rini, C. P. (2017). Pengaruh Pendekatan SETS (Science Environment, Technology, and Society) Terhadap Keterampilan Proses Sains Siswa Sekolah Dasar. Jurnal Ilmiah Pendidikan Dasar, 2(1), 59-60.

Risdianto, E., Dinissjah, M. J., Nirwana, \& Kristiawan, M. (2020). The effect of Ethno science-based direct instruction learning model in physics learning on students' critical thinking skill. Universal Journal of Educational Research, 8(2), 611615. https://doi.org/10.13189/ujer.2020.08 0233

Rofiqah, S. A., Widayanti, \& Rozaqi, A. (2020). Thinking Aloud Pair Problem Solving (TAPPS) Method: The Effect of Understanding Physics Concepts and Communication in High Schools in Indonesia. Young Scholar Symposium on Science Education and Environment 2019, 1-8. https://doi.org/10.1088/17426596/1467/1/012066 
Sari, A. C., Kartikawati, S., \& Prastyaningrum, I. (2021). Pengaruh Model pembelajaran Gallery Walk Melalui Pemanfaatan Media PhET Terhadap Kemampuan Berpikir Kritis Siswa. Jupiter (Jurnal Pendidikan Teknik Elektro), 6(1), 16. http://ejournal.unipma.ac.id/index.php/JUPI TER/article/view/8921

Sukitman, T. (2016). Internalisasi Pendidikan Nilai Dalam Pembelajaran (Upaya Menciptakan Sumber Daya Manusia yang Berkarakter). Jurnal Pendidikan Sekolah Dasar, 2(4), 86.

Susiloningsih, W. (2016). Model Pembelajaran CTL (Contextual Teaching and Learning) Dalam Meningkatkan Hasil Belajar Mahasiswa PGSD Pada Mata Kuliah Konsep IPS Dasar. Jurnal Pendagogia, 5(1), 57.

Wahyudi, W., Waluya, S., Suyitno, H., \& Isnarto, I. (2020). Students' creative thinking ability and thinking schemata in cool-critical-creativemeaningful (3CM) learning. International Journal of Innovation, Creativity and Change, 11(10). 